\title{
Article
}

\section{Materialities of mundane care and the art of holding one's own}

Brownlie, Julie and Spandler, Helen

Available at http://clok.uclan.ac.uk/17019/

Brownlie, Julie and Spandler, Helen ORCID: 0000-0002-0970-5141 (2018)

Materialities of mundane care and the art of holding one's own. Sociology Of Health and IIIness, 40 (2). pp. 256-269. ISSN 0141-9889

It is advisable to refer to the publisher's version if you intend to cite from the work. http://dx.doi.org/10.1111/1467-9566.12574

For more information about UCLan's research in this area go to http://www.uclan.ac.uk/researchgroups/ and search for < name of research Group>.

For information about Research generally at UCLan please go to http://www.uclan.ac.uk/research/

All outputs in CLoK are protected by Intellectual Property Rights law, including Copyright law. Copyright, IPR and Moral Rights for the works on this site are retained by the individual authors and/or other copyright owners. Terms and conditions for use of this material are defined in the policies page.

\section{CLoK}

Central Lancashire online Knowledge www.clok.uclan.ac.uk

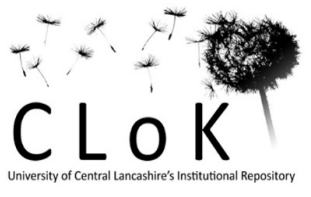




\section{Materialities of mundane care and the art of holding one's own}

\begin{tabular}{|r|l|}
\hline Journal: & Sociology of Health and Illness \\
\hline Manuscript ID & SHI-00216-2016.R2 \\
\hline Manuscript Type: & Original Article \\
\hline Subject Area: & $\begin{array}{l}\text { Emotions < RESEARCH AREAS, Social support < RESEARCH AREAS, } \\
\text { Space/spatial factors < RESEARCH AREAS }\end{array}$ \\
\hline Abstract: & $\begin{array}{l}\text { The focus of this special issue is on how everyday or 'mundane' } \\
\text { materialities actively mediate health and care practices. This paper extends } \\
\text { this concern with the mundane to care itself and explores how specific } \\
\text { materialities, such as shared spaces and everyday objects, not only } \\
\text { mediate but enable mundane care to happen. Our focus is on mundane } \\
\text { help in the context of ill-health, between people who are not immediate } \\
\text { family, such as neighbours, acquaintances and others we interact with in } \\
\text { our daily lives. Drawing on recent empirical studies of low level support in } \\
\text { two different parts of the UK, we show how materialities of care can } \\
\text { mediate the affective risks associated with receiving such help. Specifically, } \\
\text { we investigate how materialities help people to balance the expression of } \\
\text { vulnerability with a need to retain their dignity, a practice Arthur W. Frank } \\
\text { (2010) refers to as 'holding one's own'. In doing so, we argue that } \\
\text { materialities are not just the conduits for care - what care passes through } \\
\text { - or things that mediate care. We suggest instead that materialities are } \\
\text { part of how relationships of mundane care are constituted and maintained. }\end{array}$ \\
\hline
\end{tabular}




\title{
Materialities of mundane care and the art of holding one's own
}

\author{
Key words: materialities; new materialism; everyday help; informal support; ill-health; \\ shared spaces and objects. \\ Article Length: 7412
}

Seeking and accepting help in everyday life is shaped by two key paradoxes. First, this type of help is both mundane and highly significant: ordinary practices and interactions create and maintain connections between people (Fine and Glendinning 2005) which, in turn, render life liveable. Second, despite being an 'everyday' occurrence, the giving and receiving of low level support is subject to 'complex negotiations' (Breheny and Stephens 2009: 1309). In other words, the 'decision-making ecology' (Lindley et al 2012) of informal support, embedded as it is within an affective and moral economy shaped by familial, local and societal expectation, does not 'just happen'. To this extent, acts of mundane care - very ordinary acts and interactions of help and support - can be understood as 'achievements' (Anderson et al., 2015) and are all the more remarkable for rarely being explicitly reflected upon or articulated (Allen et al. 2015)

Balancing the need for help with retaining one's own dignity (Breheny and Stephens 2009) is something we all have to manage, but is especially difficult in the context of illness and in a sociopolitical climate which increasingly valorises 'independence' and demonises 'dependence'. Frank (2010) refers to this balancing act as the art of 'holding one's own' and 
has written extensively about how we often cultivate stories about ourselves to help practise this art, specifically in response to threats to self, such as ill health. This article explores how people are able to hold their own thorough materialities of care, including the stories, they tell about them. There is a well-established body of sociological literature around place-based practices of care, neighbouring and community support (see for example, Gottlieb 1981; Phillipson et al 2001) including recent work exploring how people who live with chronic illness or disability position themselves as active agents (Sakellariou 2015), thus effectively 'holding their own'. The role of mundane materialities in these practices, however, is underexplored.

This special issue concerns how 'mundane' materialities actively mediate health and care practices. Our aim is to extend the notion of mundaneity to care itself; and then to argue that materialities are core, not just to how mundane help is mediated, but to how it happens at all and to how we 'hold our own'. The range of skills and resources linked to everyday help and support - the ability to drive, offer childcare, provide a meal and so on are clearly 'material' to the extent that they are about places, buildings and objects. But materialities are not just what passes between people - or what people pass through - they are part of how relationships are constituted (Anderson et al, 2015). New materialism, in committing to a post anthropocentric approach (Braidotti, 2013), asks that we pay attention to human/non-human assemblages and the multiple relations within them which include objects, people, relationships, emotions, resources, buildings as well as economic or legal processes, and cultural practices and expectations such as reciprocity. All these elements, new materialists suggest, have material effects. 
The relations around any practice -in our case, mundane help - need to be understood through their interplay. Relations are extensive and, as such, we have been selective. For instance, while economic relations are at work in the assemblage of informal care, this has not been included here. Our aim is to use empirical data to explore how the assemblage that is mundane care happens when the care is indirect and informal. Through doing so, we argue that the materialities involved in this type of care - what one of our participants describes as caring 'by the by,' or what we have previously referred to as caring 'around the edges' (Anderson et al, 2015) - are core to how care comes about.

Drawing on our recent research on low-level care in two different parts of the UK, we move the concern with materialities beyond traditional medical and health settings (Martin et al. 2015; van Hout et al. 2015) to everyday contexts. Our focus is on mundane help that takes place in the context of ill health between people who are not immediate family, such as neighbours, acquaintances and others interacted with regularly or fleetingly, in our daily lives. The following section briefly revisits the literature that informs our analysis.

\section{Mundane material}

The 'new materialist' turn in social science and humanities (Brown 2004; Chapman 2006; Fox 2016) has focused on extending analysis to 'involve non-human agents, materials and technologies' (Martin et al 2015: 1016). New materialists claim that 'agency' - the actions that produce the social world - extends, beyond human actors, to the non-human and inanimate (DeLanda, 2006; Latour, 2005); that everyday materialities are not only a repository of meanings but are 'generative of actions and reactions' (Martin et al. 2015: 1011) including those relating to care. 
This emphasis on the generative distinguishes the materialities of care literature and adds to earlier research about how spaces and places enable wellbeing and care, including the 'landscapes of care' (Milligan and Wiles, 2010: 736) and therapeutic landscapes literature (Williams, 1998; Martin et al., 2005; Willis, 2009; Cattell et al, 2008). Materialities of care research has also foregrounded the relational aspects of materialities, including the interdependency between the human and the physical. In studying our interaction with objects, Chapman (2006) argues that we need to explore the ways such interactions are influenced by wider social context, as well as by other materialities such as place and architecture (Martin et al. 2015); for example, that the layout of places and buildings has a 'deep structure' that has the potential to 'bring people together or segregate them' (ibid: 1017).

It is, however, hard to disentangle materialities from the stories we tell about them. While this narrative dimension is not the primary focus of this article, it is consistent with those who argue that stories are 'sociocultural constructs' (Fox, 2016:67) that also have material effects. Through the notion of holding one's own, we aim to show how mundane care is produced through shared materialities. We begin with an outline of the two studies and our method of reading across the two data sets.

\section{Researching mundane materialities}

We draw on two separate, but related, research projects: the 'Liveable Lives' study (JB), carried out in and around Glasgow (Anderson et al. 2015), and the 'Landscapes of Helping' study (HS), which focused on Hebden Bridge in West Yorkshire (Allen et al. 2015). Both studies were commissioned by the Joseph Rowntree Foundation to explore 'low intensity' informal support and were commissioned as part of a programme called 'Risk, Relationships 
and Trust in an Ageing Society'. The studies ran concurrently between 2013 and 2015 and both adopted a primarily qualitative multi-method approach. Ethical approval for the studies was granted by the University of Stirling and the University of Central Lancashire respectively.

The Glasgow study applied ethnographic methods across three socioeconomically diverse areas in and around Glasgow - Hillhead, Maryhill and Bearsden - including walking interviews, focus groups and observation of community spaces and organisations. In-depth interviews ( $n=44)$ were also carried out, over two meetings, with participants keeping a log in the intervening period of instances of help and support given and received, offered or accepted, withheld or declined. A smaller number of interviews $(n=15)$ were conducted with family members, friends or acquaintances of core research participants. Participants were recruited through household screening and networking to maximise diversity (for research report, see Anderson et al. 2015a and b) ${ }^{i}$.

The Hebden study initially involved a 'rapid capture' street survey ( $n=151)$ to identify a range of factors shaping everyday care (see Spandler et al., 2014). Three diverse study sites were then selected and, through observations, contextual factors which supported helping practices were identified; less visible practices of helping were accessed and individuals were recruited for interview. In-depth semi-structured interviews $(n=40)$ were carried out with a range of participants, including those living in the town: 'hill dwellers', long-term residents and new arrivals (for research reports see Spandler et al. 2014 and Allen et al. 2015) ii. 
For this paper, we jointly re-analysed our combined data. As our original research did not specifically focus on ill health, we began by sampling across both projects for instances involving ill health and illness - including both minor and fleeting periods of unwellness and chronic and acute illness. An 'instance' in this context refers to an interaction, an observation or an activity referred to in the interviews. Through this approach, we identified 15 (Glasgow) and 9 (Hebden) instances relating directly to materialities of mundane care in the context of ill health. While these represented our core sample, to make sense of the mundane care happening in relation to them, we also engaged with interview data not specifically about ill health but which illuminated mundane materialities of care in general. These materialities were a background presence and shaped interactions involving low-level help in an extant way and not just at times of ill health.

We encouraged participants in the original research to 'notice the unnoticed' (Brownlie and Anderson, forthcoming) and, in our secondary analysis, we were also open to 'incidental attention'- a 'way of looking that is almost casual' (Lyon 2013:26, cited in Martin et al. 2015) to understand the relevance of materialities 'round the edges'. As with the original studies, our methods did not allow us to simply go and 'find' our object of study: instead, we were actively involved in creating it. Our primary research methods and foci included a humancentric interview-based approach. While this could be seen as sitting uneasily with a new materialist approach, our re-reading of the data treated all the data as potentially illuminating of the assemblages of mundane care without privileging them as straightforwardly a 'resource' about how things are. For this reason, while we have included place and age range alongside a pseudonym by way of background, we have not based our analysis primarily around these characteristics. In part because these are not determining of 
actions, but also because we wished to focus on how mundane care is assembled as a first step. We hope future work will further differentiate the nature of this process.

Our analysis involved several steps: identification of cases as specified above; exchange of data to check for consistency of interpretation; comparison of data within and across cases in relation to emergent themes; and, finally, sharing of information in relation to our primary research to help enhance the distinctiveness of the new analysis.

\section{Sharing materialities}

The Glasgow and Hebden studies highlighted how aware participants were of the emotional and interpersonal 'risks' associated with giving and receiving help, such as fears of dependency and obligation. This contributed to many people's reluctance to ask for help - a social phenomenon referred to by Linders (2010) as the 'request scruple'. The norm of reciprocity was commonly seen as helping to smooth over such affective concerns (Breheny \& Stephens 2009) but could cause anxiety for those - who for reasons of aging, illness or incapacity - may be less able to reciprocate. Not surprisingly, then, while participants described the importance of background emotions linked to trust and security, many also expressed strong emotional reactions to receiving help - such as anxiety and shame - and, as a result, self-regulated their help-seeking. Yet, a great deal of everyday help did take place, suggesting that participants found ways to hold their own: to give and receive help and to mitigate the interpersonal risks involved. In the secondary analysis below, we explore the role of mundane materialities in this process. 
The re-analysis highlighted the particular significance of sharing materialities. First, in the sense of common, usually proximate, spaces such as streets and stairwells that channel people in routinised ways into particular situations and interactions, which then create the potential to recognise (but also resist) each other's needs (Oldenburg 1989; Harris, 2008; Forrest and Bridge, 2006). Secondly, in the sense of giving and receiving objects or 'things' (Brown 2004; Chapman 2006). In what follows, in relation to the first sense of sharing, we explore the significance of the proximate and routinised nature of common materialities such as shops, libraries, squares and dog walking routes. In relation to the second, we look at the sharing of non-human materialities - things that pass between people - such as pets, cooking and shopping. These two senses of sharing materialities were ways in which people could 'hold their own' and still get help from others.

\section{Sharing spaces}

Not surprisingly, 'by the by' helping is facilitated by proximity because people's needs are more likely to become known through living side-by-side and through 'crossing paths' (Harris and Gale 2014) ${ }^{\mathrm{iii}}$. Kamran, a participant in the Glasgow study, had been helping a neighbour with mobility problems with her shopping for over 7 years. Kamran describes their relationship as being maintained over the years through the sharing of materialities, and remembers the start point as growing out of incidental awareness on the shared stairwell.

Int: She [was] living in the block of flats, too? 
Kamran: Yeah [...] she was always like carrying her bags, I felt really, really bad 'cause she was alone [...] Yeah and then I just started helping her with her groceries.

(Kamran, 18-29, Maryhill, Glasgow)

Such shared proximate spaces help people like Kamran's neighbour to hold their own because they do not explicitly have to ask for help or, if they do, their physical nearness means this is not experienced as a 'big ask'.

It wasn't like too much of a big thing to ask, because we live right beside each-other and there were other places like groceries were right beside us, so it wasn't like that much.

(Kamran, 18-29, Maryhill, Glasgow)

Sharing dog walking routes leads to similar connections made through non-committal human contact or what Harris (2007: 7) refers to as 'the importance of the casual'.

\begin{abstract}
Well, I met a kinda elderly lady when I was walking my dog, and I could tell this lady was quite lonely $[. .$.$] I eventually got to know her [...] She was needing radiotherapy,$ and she just needed somebody[...] just to make sure she was fine, or had a time for a wee cuppa. [...] When I stay, or if I'm up at my mum's, I'll always go down, but that was just like me and my dog, her wi' her wee dog, and just saying "hello" to somebody that a wee friendship built up. (Maryhill Focus Group, Glasgow)
\end{abstract}

In Glasgow, such sharing may happen in tenement stairwells. In Hebden, it often resulted from jointly owned or common land where shared access encourages a level of civility between neighbours so that they often hold each other keys - a practice which is seen to 
signify trust (Harris and Gale 2004). The Hebden street survey surfaced several examples of this, and conversely, the risks of not sharing proximal materials. One participant described how, after a flood, neighbours who held each other's keys were able to enter each other's houses and save belongings and pets. Conversely, newcomers who had sought to maintain their privacy by creating barriers between residences found that these trapped the water, causing worse flood damage. Mundane care, however, can also, be experienced as oppressive and sharing proximate spaces then becomes a mixed blessing.

'I always try and avoid Margaret because she's always, I don't know, "You're doing so well because you've got cancer and you know it's a..." [Sighs] but I also want her to look after the cat when I'm away so [laughs].

(Elizabeth, 70-79, Hillhead, Glasgow)

Outside the immediate residential environment, there are other spaces that are shared. In Hebden, people have to cross the pedestrianised town square to get through the town, ensuring incidental contact between members of the community. Hebden is also a valley, which means people have to descend into the centre in order to reach anywhere else.

And I just think [...] that the layout of the village lends itself, one, to getting to know people, you know, because if you see the same people in the same car you eventually start waving to them and they wave. And then when you see each other you have a chat...We all know each other - it's where we live and the terrain has shaped us (Brenda, 60-69, Hebden)

The landscape affords the possibility of connections that, should it become necessary, can become sources of help. This is not just because of the incidental nature of the contact that 
happens in shared spaces but because for some - especially older men- occupying and feeling part of such civic spaces is how they hold their own. In other words, it offers a context where they are able to accept help without risk to dignity. This is very different from being offered help in one's own home or even in informal spaces where specific 'entrances' have to be made which can be exposing of vulnerability, isolation or need (Martin, forthcoming). The felt barrier of walking through a doorway was referred to by several participants. Suzie, who is physically disabled, describes what it feels like to attend her local community centre.

And especially it's two doors, if you know what I mean. You've got one big heavy door and then you've got the reception, and then you've got to open the other doors to go in, and all these women are sitting, and they're all looking at somebody coming in the door! Although they're all "Hiya" - you know what I mean? - it's still .. it is daunting. (Suzie, 50-59, Maryhill, Glasgow)

\section{Shared Routines}

Shared routines, as well as spaces, can be helpful not just in facilitating help, should it become necessary, but because of the way they allow people to feel looked out for, to feel 'known'. In the following extract, Elizabeth describes her trips to her local supermarket:

I like the idea of being known. You see these guys [...] in Marks \& Spencer's are local, know where I live because it's impossible for them not to, and that's important. I don't have a family... but I like to have people around me that will look out for me maybe. I mean not thinking they're looking out for me.

(Elizabeth, 70-79, Hillhead, Glasgow) 
She goes on to describe the significance of this routine after she started chemotherapy.

I went to buy [sweets], the stuff from Marks \& Spencers and I would crawl up the hill to see people and give them a sweetie and then go home you know. But it was important for me to, to make it, to be there.

(Elizabeth, 70-79, Hillhead, Glasgow)

Routines ensure some people become 'regulars' so their absence is 'quickly noted'

(Oldenburg 1999: 39), protecting against 'the kind of lack of community that is formulated when someone becomes ill or dies in their house and nobody noticed' (Laurier, 2002: 8, in Warner at al. 2013: 309). As Elizabeth's account of being 'known' illustrates, one setting where this happens is local shops. In an outlying village near Hebden, there is a community shop: a small space packed full of 'essentials' with a bulletin board, a visitors book and a chair by a fire for people to have a 'sit down'. This seat is important not just for those in need of rest but because it allows people to 'linger' (Cattell et al., 2008) long enough to connect with others. This is what Martin (forthcoming), drawing on Hand and Shove (2004), describes as the orchestrating effect of objects. In many ways the shop reflects Oldenburg's (1999) description of the third place as 'typically plain', repelling in the process 'the transient middle-class customer' (p. 36). Its regular and routinised use by 'locals' enables connections to be made and information to travel but, again, it is the not 'having to ask' that keeps affective risks at bay. One customer who had experienced a heart attack elsewhere commented that this became known about through the shop:

Everybody rallied round. I just didn't need anything did I? I had too many meals, I couldn't eat them quick enough. Everybody just came. (Flo, 70-79, Hebden) 
Whilst it is tempting to romanticise the independently-owned rural shop as a traditional hub of helping, such shared materialities can also operate in similar ways in urban contexts and even in scaled-up, corporate settings such as supermarkets. Here again there is a sense of relationships being layered up through material practices.

You start getting that used to your customers and building up that much of a rapport with them, so when they're not in, you start worrying. There's like old Tommy, he's in every single morning, and then he comes back in the afternoon. He brings me my paper in the morning, so he does.

(Supermarket employee 1, Maryhill, Glasgow)

Surprisingly, perhaps, given the apparently uniform character of corporate supermarkets, staff also note differences between branches, pointing to the varied meaning the same materiality can have depending on the area and beliefs about the impact of the socioeconomic context.

From working in [names wealthy area of Glasgow] I think it's a lot different [in Maryhill]. I don't know, it's maybe just because [other area] is politer, posher, I don't know. So they come through, they have the shop and then they're away [...]. But the relationship we've got in this shop [...], I mean the customers will come in at a particular time and a particular day when that staff members in and that staff member will be in the shop and they'll know who's coming in at seven who's coming in at half eight to the shop, and if they're not there, they're like, "where are they today?" 
(Supermarket employee 2, Maryhill, Glasgow)

\section{Contingent spaces and materialities}

Materiality is fluid and neither it, nor the relationships it materialises, can be taken for granted. Its contingency can lead to new possibilities. In Hebden, for instance, there were many examples of people taking the initiative to develop shared green spaces-for example, reclaiming unused land for dog walking, shared gardening or play areas. It can also, however, lead to losses. The participant below, for example, notes how a change in supermarket layout led to the loss of older customers:

We lost a lot of customers. We thought it was gonna be the same [...] which is food downstairs and other goods, non-food and what have you upstairs, so we had a lot of elderly in the area, we lost them. They're away, either go to Morrisons or a lot of them still come but they struggle because it is so big and a lot of them use either a wheelchair or the buggy. (Supermarket employee 3, Maryhill, Glasgow)

Similarly, in Hebden, participants described the reaction when the community shop removed 'the seat' suggesting that it functioned as a communal 'special object' (Chapman 2006):

She took it out one day and I went down and I said, "where's the seat gone?" And she said, "oh we've moved it out". I said, "well that's no good for somebody who's walked down the valley like me". I said, at my age, so she put it back. (June, 70-79, Hebden) 
The idea of shops as a 'safe space' also resonates with how people think and talk about other public buildings, including libraries. These, too, can be safe spaces where people can count on being noticed and acknowledged as well as given support 'round the edges' in the form of physical and emotional comfort.

\begin{abstract}
Some of these people have nobody else to talk to, so they'll come in here, which is nice, that they feel comfortable enough to come in and chat [...] They're getting an environment they can come and sit in relative safety, that's fairly warm (Member of library staff, Hillhead, Glasgow)
\end{abstract}

\begin{abstract}
Again, of course, none of this, is inevitable: the benign culture of local shops and supermarkets and public spaces like libraries are dependent upon 'permissive' organisational policies and practice, the goodwill of staff as well as shifting materialities. Mundane (material) care, in other words, operates at both interpersonal and collective levels and is open to institutional and socio cultural change. Access to such public spaces and buildings, moreover, is differentiated with many examples across both studies of exclusions based on class, nationality or ethnicity. For example, while Hebden is socially mixed in some ways, with a notable lesbian/gay/bisexual presence, it is visibly a very 'white' area which has consequences for feeling included/excluded in public spaces.
\end{abstract}

Storying places 
Despite uneven experiences of inclusion, many participants across both studies drew on powerful place-based narratives - Glasgow as 'the friendly city' or the idea of Hebden Bridge as 'alternative'. In fact, sometimes they did so in the face of contradictory experiences. Fatima, for instance, referred to a racist incident she had experienced in Maryhill before stating shortly afterwards:

If you go to England, nobody wants to know you.[...] But if you come to Glasgow, they're all friendly. Every part is friendly, as far as I know that. (Fatima, 40-49, Maryhill, Glasgow)

Resonating with Frank's (2010) privileging of the role of stories in connecting people and enabling them to hold their own, the storying that Fatima and others do is part of how materialities are allowed to generate care. In both studies narratives of place helped (re)produce a sense of shared pride and attachment to place - that, in turn, fuelled confidence, connection and reciprocity and, as we have argued elsewhere, this helps to do the work of enabling support to take place (Allen et al 2015, 2015; Anderson et al. 2015).

\section{The things that pass between people}

So far we have looked at common materialities such as buildings and land, but discrete 'entities' or things such as shopping, food and animals are also part of the assemblage of mundane care. These help to shape practices of mundane care as they are one step removed from the (inter)personal risks of direct help. It is precisely the mundane and everyday nature of things like animals and food that means they can be readily incorporated 
into people's daily routines - they are 'nothing special', allowing people to hold their own more effectively. More than this, however, we are suggesting that they actually work to constitute the relationships through which the practices of mundane care happens.

\section{Dogs, sheep and hidden helping}

Mike, a retired professional and long term resident of Bearsden, who lives with his wife and dog, is involved in mundane but, nonetheless significant, care for their ill next door neighbour who has young children. Through sharing a window cleaner in the first instance, 'that's probably how it started that there would be a conversation when they brought the money kind of thing' - Mike and his wife now offer a range of low-level help. For example, they take the neighbour's children for a walk with their dog and they also 'lend' their dog to the neighbour. It is the dog that materialises the ongoing relationship. Returning to the interdependency of humans and 'things', the dog and neighbours 'enable each other to be' (Frank 2010): from the children's perspective, it is the dog not Mike, they are walking with and for the neighbour, it is the dog, not Mike and his wife, offering the respite:

And of course with the dog, the kids love the dog as well so I mean they don't really notice us they just think they're going for...it's not 'are you coming a walk with us', it's 'are you coming a walk with the dog?' Its great! The neighbour will take the dog for a walk, it gets her out of the house (Mike, 60-69, Bearsden, Glasgow)

Mike describes these practices as simultaneously 'not really a big deal' and 'such a big help' as it enables his neighbour 'to do the mundane things that you have to do in the house you know?' Belying the ordinariness of all of this is the art of recognising the need as legitimate while ensuring the help is not a big deal and even pleasurable. Also underlying the 
pedestrian nature of such acts is the considerable, if unnamed, trust involved in allowing others to care for us and our significant others.

The dog-walking referred to so far has been routinised but the relationship we have with non-human entities, including animals, are not always within our control:

\author{
'The human who is conditioned to efficiency and pressured by time, tries to go in \\ straight lines: but the dog, moving smoothly along irregular invisible trails, \\ preoccupied with the data-barrage of scents or sounds, can pull its owner off-line'. \\ (Harris 2007: 85).
}

Being pulled 'off line' can also enable mundane care to happen. While this is not a shared materiality in the same sense as a pet is, the following extract does illustrate how, in some landscapes, other animals can also enable 'hidden helping' to occur, in this case help without contact, through what might be called 'watchfulness'iv:

\footnotetext{
He's a sheep farmer...and his wife's got cancer and there is this kind of sense that, in our small community anyway, because all of the fields around us are his fields, that you don't want to trouble him. So, you know, [...] if there's a sheep out, if you can get it in yourself, then you do it [...] even though he'll never know about it (Brian, 5059, Hebden) (emphasis added)
}

Avoiding the big ask: cooking and shopping by the by 
Not surprisingly, given the taken-for-granted role that food has in our everyday lives (Valentine, 1999), it is a common means of offering help 'by the by'. Across both data sets there were examples of shopping and cooking, enabling relationships of mundane care to be started or maintained. In the following extract, Mike describes how he and his wife cook for their neighbours. Part of establishing that this is not a 'big ask' is to subsume the help into something that would be happening anyway. In other words, materialities are given or shared through a narrative that suggests this is happening at no extra cost.

It's not a great onus on us um...basically we'll cook maybe once a week whatever but I mean we're cooking anyway so it's not a big deal.

(Mike, 60-69, Bearsden, Glasgow)

A similar narrative of incidental helping is offered by Liam - this time shopping for a friend's mother is subsumed under the primary activity of going to the health centre.

And I need to go into the health centre every day to get the methadone. And my big mate's ma', she just stays next to the health centre anyway... I go up and see her. I get her what she wants in the morning an' all that [...] and I just go up the health centre.

(Liam, Maryhill, 40-49, Glasgow)

Through telling these particular stories about materialities, the affective risks that could undermine Mike's neighbours, or Liam's friend's mother's, ability to hold their own is managed. There are temporal dimensions to this type of help - Mike and Liam, for instance, may have more flexibility to help because they are not working. Such cases also raise the issue of mutuality and the ways in which caring, even in a low key way, offers something 
back, such as a sense of purpose, to the helper. This 'reward' is acceptable exactly because it, like the help, is not explicitly named. There are clearly also gendered dimensions to mundane help. Mike, for instance, comments that 'my role is to simply to go and buy the ingredients. Um...I have a minor role in it'. It appears, then, that the cooking may, in fact, be his wife's work and the earlier account of this as not a 'big deal', Mike's interpretation. More generally, however, understanding how mundane materialities of care are assembled requires a gendered lens because of the tendency to recognise practical help when it occurs but for emotional support - which is more likely to be done by women - to be discounted (Allen et al, 2015; Anderson et al, 2015; Brownlie, 2014). While this may speak to the visibility of certain forms of help, it also speaks to the kinds of help that are valued. For men, in particular, it is often the practical dimension and material context of interactions neither explicitly tied to help - which enables them to accept support and hold their own. This is why recent innovative health initiatives use men's sheds and football venues to offer support (Ballinger et al 2009; Spandler et al. 2014).

\section{Holding Back}

Shared materialities, like pets or food, facilitate mundane care but are, like shared spaces and buildings, no guarantee of it. There were cases across the two data sets where people experiencing ill health were unable to give or receive materialities. Often, this was to do with norms such as those relating to reciprocity, which in some cases are so powerful they override the relational potential of materialities. These norms are experienced through a range of lenses including gender, class, age, location and relationship status. Sophie, in her thirties with two young children, whose own family live some distance away, believes there 
is a norm in predominantly middle class Bearsden that families 'care for their own' which means she has not been able to have her offers of child care accepted. Without a material inroad to helping she feels unable to ask for help in return.

Ivan, a man with chronic health problems and limited economic resources in the Glasgow study, had no entries in his log after two weeks, despite being very unwell for the whole of this time and recognising that shared materialities such as food and shopping would have made a difference: 'it would have been nice for someone to make me a simple meal, um...something you know'. A self-defined 'middle-class' man who moved to a predominantly working class area of Maryhill, he felt unable to connect to others with whom he felt he had 'nothing in common'.

This isolation makes it difficult for the 'by the by' type helping - such as the sharing of a 'simple meal' - to happen. Ivan's isolation is, however, reinforced by his belief that because of his ill health and financial circumstances, he is viewed by others as no longer capable of offering help. Like Sophie - albeit for different reasons - he finds himself unable to ask for help.

Ivan: These days the less you have people tend not to bother you! They say "oh he can't help so"...

Int: Is that around material things or is that around physical strength or -

Ivan: Well material things, physical strength [...].

(Ivan, 60-69, Maryhill, Glasgow) 
Our focus in this section has been on how the sharing of materialities helps constitute relationships that can produce mundane acts of care. Of course, as Ivan's and Sophie's accounts show, not everyone is able to access shared materialities and, clearly, help is possible without such materialities. Our argument here, however, is that mundane materialities can have a significant role, even in cases of quite serious ill health, not only in mediating care but in producing the relationships that are necessary for care to happen.

\section{Concluding thoughts: assembling mundane care}

Our aim in this article has been to extend the notion of mundaneity to care, and then to explore the role of mundane materialities in helping us to 'hold our own'; that is, to access help in a way that does not undermine our sense of dignity.

This concern with the role of materialities in mundane care or 'mundane care in-andamong-the-things-of-the-world'v ${ }^{\text {, }}$, highlights the relevance of the slight or what we have referred to elsewhere as the 'unnoticed' (Brownlie and Anderson, forthcoming). We have looked at how things - from doors, to seats and dogs - can allow us to look out for each other in both fleeting and sustained ways. The slightness of some of these interactions is not easily captured by 'heavier' sociological theories around assemblages, social capital or care. Yet we do need a way of conceptualising the complex, if unnoticed, role of the material in such care. In particular, we need to find ways of conceptualising materialities that allow for how they are shared interpersonally but also at a collective level; their, at times surprising, contingency; and the differentiated nature of our interaction with them. Past conceptual work on landscapes of care and public spaces offered ways of engaging with the spatial 
context of materialities, and identified, if it did not fully conceptualise, the significance of the mundane material (Holland et al. 2007). Recent work from a new materialist perspective, in addition to focusing on context through place and time, has paid more attention to the micro, generative and interdependent nature of person-object relations. This has helped to make sense of the precariousness of things and our relation to them or, in our analysis, the possibilities for small acts of care to emerge in and through sharing the most ordinary of spaces and things.

There are risks that a materialities approach which spotlights human emotions in an otherwise flat ontological landscape, underplays the way material effects shape emotions and vice versa. There has been an increasing awareness of the emotional attachment to objects from those interested in postsocial relations (e.g. Cetina and Bruegger 2013), but the emotional salience of mundane materialities requires further consideration. We have made a case here for the significance of mundane material in helping us 'hold our own'. It enables us to get help 'by the by' and 'around the edges' through things that are part of our daily lives - objects, animals and places - and in ways which are barely noticed, thus helping us maintain our dignity. Indeed holding one's own can be understood as a type of emotional work, and materialities as a fundamental part of how this emotional work is achieved. They allow for the affective and interpersonal risks associated with helping and being helped, such as shame and embarrassment, to be managed or minimised, thus building interpersonal trust.

Through looking at shared materialities we illustrated how informal helping actually works in practice, and how it frequently happens in an understated way through relationships 
between people, spaces and things. This work is also achieved through the stories we tell about materialities, including the positioning of such help as happening 'anyway' or through broader narratives of place. Looking at the various relations that make up the assemblage that is mundane care - including bodies, emotions, stories, shops, landscapes, animals, stairwells and stories - it is clear that materialities are not just what care passes through but rather what makes possible relationships, and therefore the potential for care. This distinction matters because thinking of materialities as conduits or merely the 'backdrop' to care assumes that relationships already have to be established for materialities to be shared. What we have emphasised here is the productive relational and emotional possibilities of mundane materialities.

\section{References}

Allen, M. Spandler, H. Prendergast, Y. and Froggett, L. (2015) Landscapes of Helping: Kindliness in neighbourhoods and communities. Joseph Rowntree Foundation, York. Anderson, S. Brownlie, J. and Milne, EJ (2015) The liveable lives study: understanding everyday help and support Joseph Rowntree Foundation, York

Ballinger, Megan L., Lyn A. Talbot, and Glenda K. Verrinder. (2009) "More Than A Place To Do Woodwork: A Case Study Of A Community-Based Men's Shed", Journal of Men's Health, 6,1, 20-27.

Braidotti, (2013) The Posthuman Cambridge: Polity Press

Breheny, M., \& Stephens, C. (2009) I sort of pay back in my own little way: Managing independence and social connectedness through reciprocity, Ageing and Society, 29, 8 , $1295-1313$ 
Brown, B. (2004) Thing theory. In B. Brown (Ed.), Things (pp. 1-21). Chicago, IL: The University of Chicago Press.

Brownlie, J. (2014) Ordinary Relationships. A Sociological Study of Emotions, Reflexivity and Culture New York: Palgrave MacMillan

Brownlie, J. and Anderson, S. (forthcoming) Thinking Sociologically about Kindness.

Puncturing the Blasé in the Ordinary City Sociology

Burkitt, I. (2014) Emotions and Social Relations London: Sage

Cattell, V. Dinesb, N. Gesler, W. Curtis, S (2008) Mingling, observing, and lingering: Everyday public spaces and their implications for well-being and social relations. Health and Place, 14, 3. $544-561$

Cetina, K.K, Bruegger, U (2013) Traders' Engagement with Markets A Postsocial Relationship Theory, Culture \& Society December 2002 vol. 19 no. 5-6 161-185

Chapman, S.A. (2006) A 'new materialist' lens on aging well: Special things in later life, Journal of Aging Studies, 20, 3, 207-216

DeLanda, M. (2006) A New Philosophy of Society London: Continuum

Fine, M. and Glendinning, C., (2005) Dependence, independence or inter-dependence?

Revisiting the concepts of 'care' and 'dependency' Ageing \& Society 25: 4:601-21

Forrest, R. and Bridge, G. (2006) What is neighbourliness?. In Pilch, T. Neighbourliness. London: The Smith Institute 
Fox, N.J. (2016) Health sociology from post-structuralism to the new materialisms Health,.

$20,1,62-74$

Frank, A. W. (2010) Letting Stories Breathe: A Socio-Narratology University of Chicago Press.

Gottlieb, B (1981, ed.) Social Networks and Social Support Beverley Hills, Calif:

Sage

Hand, M. \& Shove, E. (2004) Orchestrating concepts: kitchen dynamics and regime change in Good Housekeeping and Ideal Home, 1922-2002. Home Cultures, 1, 235-256

Harris, K. (2003) 'Keep your distance: remote communication, face-to-face, and the nature of community, Journal of community work and development, 4(1)

Harris, K. (2007) 'Dog breaks ice: the sociability of dog walking' in: Making links: fifteen visions of community. London: Community Links

Harris, K. (2008) Neighbouring and older people: an enfolding community? London: Community Development Foundation

Harris, K .and Gale, T. (2004) Looking out for each other: the Manchester neighbourliness Review. London: Community Development Foundation

Latour, B. (2005) Reassembling the Social. Oxford: Oxford University Press

Lindley, E., Broome, S., Dellot, B., Norris, E., Rowson, J., Soopramanien, D. and Truch, E. (2012) Improving decision-making in the care and support of older people: exploring the decision ecology. York: Joseph Rowntree Foundation 
Lyon, D. (2013) The labour of refurbishment: the building and the body in space and time. In Pink, S. and Tutt, D. (eds) Ethnographic Research in the Construction Industry. London, Routledge

Martin, D, Nettleton, S, Buse, C, Prior, L and Twigg, J (2015) Architecture and health care: a place for sociology. Sociology of Health and IIIness, 37, 7, 1007 - 1022.

Martin, D. (forthcoming) Curating Space, Choreographing Care: The Efficacy of the Everyday. In C. Bates (ed) Bodies, Building and Design London: Wiley Blackwell

Milligan, C. and Wiles, J. (2010) Landscapes of Care Progress in Human Geography, 34, 6, 736-754

Oldenburg, R. (1989) The great good place: cafes, coffee shops, community centers, beauty parlors, general stores, bars, hangouts, and how they get you through the day. New York:

Paragon House

Phillipson, C., Bernard, M., Phillips, J. and Ogg, J. (2001) The Family and

Community Life of Older People: Social Networks and Social Support in Three Urban

Areas. London: Routledge.

Sakellariou, D. (2015) Enacting Varieties of Subjectivity Through Practices of Care: A Story of Living With Motor Neurone Disease. Qualitative Health Research, 19, 1, 21-38.

Valentine, G. (1999) Eating in: home, consumption and identity. The Sociological Review, 47, 3, 491-524.

Spandler, H. Allen. M. Prendergast, Y and Froggett, L. (2014) Informal Support in a Yorkshire Town. Joseph Rowntree Foundation, York. 
Spandler, H. Roy, A. Mckeown, M. (2014) Using football metaphor to engage men in mental health services. Journal of Social Work Practice. 28(2) 229-245

van Hout A, Pols J, Willems D, (2015) Shining trinkets and unkempt gardens: on the materiality of care. Sociology of Health and IIIness 37, 8, 1206-1217

Warner, J. Talbot, D. and Bennison, G. (2013) The cafe as affective community space: reconceptualising care and emotional labour in everyday life. Critical Social Policy, 33, 2, 305-324.

Williams, A., (1998). Therapeutic landscapes in holistic medicine. Social Science \& Medicine, $46,9,1193-1203$.

Willis, A. (2009) Restorying the self, restoring place: Healing through grief in everyday places Emotion, Space and Society, 2, 2, 86-91

Acknowledgements

We would like to thank the Joseph Rowntree Foundation for funding both the Hebden and Glasgow studies and particularly Ilona Haslewood for her patience and support throughout. We would also like to thank all the participants and community organisations that took part in the research and the project advisory boards. Thank you in addition to the following members of the research team at Edinburgh University, ScotCen Social Research and NatCen Social Research: Simon Anderson, E-J Milne, Jo Neary, Martin Mitchell, Anna Marcinkiewicz and Susan Reid. Thank you also to the Hebden Bridge research team: Meg Allen, Yvonne Prendergast and Lynn Froggett and to Irene Anderson for editing and proofreading services. 


\footnotetext{
' Of the 59 Glasgow interviewees, 19 were from Bearsden, 23 from Hillhead and 17 from Maryhill; 30 were males and 29 female; 12 were aged 18-29, 9 were aged 30-39, 12were aged 40-49, 6 were aged 50-59, 7 were aged 60-69, 11 were aged 70-79, and 2 were aged 80-89; 26 were owner occupiers, and 33 lived in rented accommodation.

ii Of the 40 Hebden interviewees, 22 were women and 18 men; 3 were aged 18-29; 5 were 30-39; 7 were 40-49; 10 were 50-59; 10 were 60-69 and 5 were 70-79. The sample for re-analysis reflected the diversity of the original studies but given the focus on ill health, was, unsurprisingly, a slightly older sample.

iii These paths could, of course, be 'virtual' though that does raise other issues about translation to offline help (Harris 2003).

iv Thank you to one of our reviewers for this framing

${ }^{\vee}$ Thank you to one of our reviewers for this description.
} 